\title{
Formação de conceito sobre a natureza do conhecimento científico utilizando a teoria de P.Ya Galperin a partir da história da química
}

\author{
Formation of a concept of nature of scientific \\ knowledge using the theory of P.ya \\ Galperin from the Chemistry History
}

\author{
Robson Fágner Ramos de Araújo ${ }^{1}$ \\ João Pessoa Pires Neto ${ }^{2}$
}

\begin{abstract}
RESUMO
O presente artigo teve como objetivo analisar a formação de conceitos dos estudantes do ensino médio, sobre a natureza do conhecimento científico a partir da História da Química relacionado ao episódio do "sonho" de August Kekulé, utilizando-se a possibilidade metodológica da Teoria da Formação por Etapas das Ações Mentais, proposta por Galperin (1982). Para tanto, foi aplicado uma sequência de ensino em uma turma do $3^{\circ}$ ano do Ensino Médio em uma escola estadual da cidade de Campina Grande PB. Os resultados apontam para as possibilidades metodológicas na organização de atividade de ensino voltada à formação de conceitos científicos e compreensão no processo do desenvolvimento científico, por meio da assimilação das etapas operacionais orientadas pela Base Orientadora da Ação, evidenciadas nas atividades desenvolvidas no espaço escolar.
\end{abstract}

Palavras-chave: Formação de Conceito. Teoria de P.Ya Galperin. Ensino de Química.

\begin{abstract}
This article aimed to analyze the formation of concepts of high school students, on the nature of scientific knowledge from the History of Chemistry related to the episode of August Kekulé's "dream", using the methodological possibility of Formation Theory by Stages of Mental Actions, proposed by Galperin (1982). For that, a sequence of teaching was applied in a class of the 3rd year of High School in a state school in the city of Campina Grande - PB. The results point to the methodological possibilities in the organization of teaching activities aimed at the formation of scientific concepts and understanding in the scientific development process, through the assimilation of the operational steps guided by the Action Orientation Base, evidenced in the activities developed in the school space.
\end{abstract}

Keywords: Formation. Galperin's Theory. History of Chemistry.

\footnotetext{
${ }^{1}$ Escola Cidadã Integral Técnica Arlinda Pessoa da Silva. ORCID: https://orcid.org/0000-00027155-6706. E-mail: robson.ramos.araujo@hotmal.com.

${ }_{2}$ Universidade Federal do Oeste da Bahia, Centro das Ciências Exatas e das Tecnologias. ORCID: https://orcid.org/0000-0001-7459-505X. E-mail: joao.neto@ufob.edu.br.
} 


\section{Introdução}

Um dos grandes pesquisadores da geração de psicólogos russos, P. Ya. Galperin (1902 - 1988) tinham contato pessoal com Vygotsky, o fundador da escola sociocultural em psicologia Russa. A teoria de Vygotsky surgiu a partir do contexto das primeiras décadas do século XX e representou uma nova abordagem para a psicologia. De acordo com Haenen (2001), Galperin pode ser considerado entre os que mais desenvolveram esta abordagem.

Sendo um dos membros da escola de Jarkov e dando continuidade ao pensamento de Leontiev e das ideias de Vygotsky, Galperin, criou uma teoria do desenvolvimento psíquico a partir de suas pesquisas, bem como desenvolveu um mecanismo de interiorização das ações externas em internas, em que destaca o papel das ações externas no surgimento e formação das ações mentais no processo de ensino. Nesse contexto, Núñez (2009) descreve que, para, aprender novos conceitos, novas generalizações, novos conhecimentos e novas habilidades, o aluno deve assimilar ações mentais adequadas. Isso supõe que tais ações se organizem ativamente. De início, assumem a forma de ações externas, que se formam em colaboração e, só depois, transformam-se em ações mentais internas. (p.92)

Deste modo, este princípio metodológico que passa a ser conhecido como Teoria da Formação por Etapas das Ações Mentais e dos Conceitos, descreve as etapas de uma atividade externa em interna, conhecido de processo de internalização, ou seja, essa teoria se faz importante na atividade de ensino, ao "explicar que a assimilação do conhecimento ocorre em etapas fundamentais da formação, no sentido da passagem do plano da experiência social para o da experiência individual" (NÚÑEZ, 2009, p. 93).

Nessa perspectiva, Galperin (2001) considera a aprendizagem como sendo toda atividade que tenha como resultado nova formação de conhecimento, ou novas qualidades no conhecimento que já possuam, como: as habilidades e hábitos, sendo "O vínculo interno que existe entre a atividade e os novos conhecimentos e habilidades residem no fato de que, durante o processo da atividade, as ações com os objetos e fenômenos formam as representações e conceitos" (p.85). Ainda de acordo com Galperin (2001), assimilar significa 
apropriar-se do objeto do conhecimento, em que as principais etapas nas quais a ação é realizada, representam os níveis sucessivos da transformação do objeto do conhecimento em algo mais próprio do sujeito que aprende.

De acordo com Núñez (2009), esta teoria considera a aprendizagem como sendo um tipo específico de atividade, cujo cumprimento conduz o estudante a novos conhecimentos, hábitos e ao desenvolvimento da sua personalidade, uma vez que cada tipo de atividade implica um sistema de ações unidas por um motivo que, em conjunto, assegura o alcance do objetivo da atividade que se assimila, acrescentando que o processo de assimilação do conceito é também o processo de sua aplicação em forma de atividade. Ainda de acordo com Núñez (2009), as etapas do processo de assimilação se caracterizam pelas mudanças operadas em cada uma das características da ação, a compreender: a) a forma; b) o grau de generalização; c) de independência; e e) de consciência.

Nesse contexto, Pereira (2013) relata que, Galperin considera que o processo de formação de uma ação começa com o apoio de objetos concretos ou reais (objetos materiais) ou sua representação (objetos materializados) e passa para as etapas subsequentes (linguagem e mental), uma vez que o desenvolvimento do pensamento lógico e os conceitos das disciplinas escolares podem ser assimilados com êxito se houver um modelo planificado da atividade (habilidade). De acordo com Núñez (2009), a Teoria da Assimilação de Galperin consiste no processo de interiorização da atividade externa em atividade interna, transcorrendo as seguintes tapas: a) etapa motivacional ${ }^{3}$; b) etapa de estabelecimento da base orientadora da ação (B.O.A); c) etapa da formação da ação no plano material ou materializada; d) etapa da formação da ação na linguagem externa; e) etapa da ação no plano mental.

\section{A natureza do conhecimento científico}

Uma aprendizagem científica significativa no campo das ciências naturais requer "compreender como os cientistas trabalham e quais as limitações de seus

\footnotetext{
${ }^{3}$ A etapa motivacional no processo de assimilação de uma habilidade é defendida por Talízina (1987), referindo-se como "etapa zero", ou seja, quando não há nenhum tipo de ação na qual sua tarefa principal seria a criação de uma motivação necessária ao estudante.
} 
conhecimentos" (SANTOS, 2007. p.483), ou seja, conhecer e compreender a natureza do conhecimento científico é necessário ter conhecimentos sobre História, Filosofia e Sociologia da Ciência.

De acordo com Abd-El-Khalick (2012), o conhecimento científico é produzido por comunidades que variam a partir de equipes de pesquisadores da área, em vez de grandes grupos organizados por disciplinas científicas e subdisciplinas. Nesse sentido, Porto (2011) acrescenta que "o estudo da história da ciência pode contribuir para a construção de visões sobre a natureza da ciência mais coerente com o pensamento atual dos filósofos dessa área” (p.170).

Segundo Santos (2007), o caráter provisório e incerto das teorias científicas, os alunos podem avaliar as aplicações da ciência, levando em conta as opiniões divergentes dos especialistas, ao invés de uma visão de ciência como algo absolutamente verdadeiro e acabado, em que os alunos terão dificuldade de aceitar a possibilidade de duas ou mais alternativas para resolver um determinado problema, ou seja, é necessário conhecer os conceitos científicos, mas também, de se ter um conhecimento sobre a Natureza da Ciência - NdC,e sua dimensão histórica, filosófica e social, como forma de se desenvolve a atividade científica. Matthews (1994), ensinar sobre o conhecimento científico requer a discussão da natureza do conhecimento científico, podendo ser contemplada por meio da HFC, conduzindo os alunos a uma melhor compreensão dos conceitos e dos métodos da ciência.

Nesse viés, Abd-el-khalick e Lederman (2000), existem dois tipos de abordagens que podem possibilitar a inserção de conteúdos pautados na Natureza da Ciência no processo de ensino e aprendizagem, a implícita, em que assume a construção do conhecimento como consequência do engajamento no processo pedagógico, onde os trabalhos devem possibilitar a inserção do aluno em atividades investigativas, incluindo instruções sobre a prática científica, e abordagem explícita, em que os objetivos e materiais instrucionais são direcionados para aumentar a compreensão da Natureza da Ciência, de forma a incluir a discussão dos conteúdos epistemológicos, bem como as atividades planejadas a serem incluídos nas investigações.

Nessa perspectiva, Hodson (2009) afirma que a natureza do conhecimento 
científico, os métodos de investigação da ciência e da linguagem da ciência estão intimamente ligada a uma discussão de qualquer um dos aspectos, e consequentemente reforçada pela discussão dos outros, reforçado por uma apreciação da história, tradições, normas e valores subjacentes da ciência.

Percebe-se que, abordagens sobre as concepções relacionadas à natureza da ciência nos componentes curriculares poderão promover um debate epistemológico com os pares envolvidos no processo de ensino e aprendizagem, a partir de rupturas epistemológicas, favorecendo dessa forma, a compreensão da descontinuidade do pensamento científico no campo das ciências naturais. Desta forma, o presente texto tem como objetivo analisar a formação de conceitos dos estudantes do ensino médio sobre a natureza do conhecimento científico, a partir da História da Química relacionados ao episódio do "sonho" de August Kekulé.

\section{Metodologia}

A pesquisa possui um caráter qualitativo, haja vista a necessidade de entender os conceitos formados pelos estudantes, segundo as concepções e seu nível de abrangência adotada pelos mesmos. A pesquisa foi realizada com 22 estudantes do Ensino Médio de uma escola estadual na cidade de Campina Grande - PB. A codificação na identificação dos estudantes foi utilizada da seguinte forma: Est. 1, Est. 2, Est. 3,..., Est. 22, preservando o anonimato dos mesmos. Os dados obtidos foram analisados utilizando a metodologia da Análise de Conteúdo, proposta por Bardin (2012).

A partir do objetivo da pesquisa foram utilizadas as possibilidades metodológicas, a partir da Teoria da Formação por Etapas das Ações Mentais proposta por Galperin (1982), que seguiu-se as seguintes estratégias: aplicação das atividades estabelecidas pelas etapas operacionais (motivacional, B.O.A do tipo II, etapa materializada, etapa externa e interna), elaboradas com base nas implicações pedagógicas da Teoria de Galperin.

A BOA tipo II, segundo Talízina (1988), se caracteriza pela existência de todas as condições necessárias para o cumprimento de correto da ação. Pois estas 
condições se dão ao sujeito, primeiro de forma preparada e, segundo, em forma particular que serve para a orientação somente em um caso dado. A atividade a ser realizada na B.O.A do tipo II será elaborada a partir de uma ficha de estudos e/ou mapas de atividade, incluindo desse modo, todos os elementos necessários para a realização da ação, ou seja, no esquema da Base Orientadora da Ação, é necessário não só introduzir o sistema de características necessárias e suficientes do conceito dado, mas também o sistema de ações que determina o tipo de atividade a ser realizada com esse conceito (NÚÑ̃E, 2009).

Núñez (2009), afirma que o sujeito (grupo de estudantes) realiza a ação por meio do mapa de atividade orientado pela BOA, estabelecendo uma série de condições necessária à realização da tarefa de modo a chegar ao objetivo de estudo, formando o conceito desejado, ou seja, a BOA se torna um sistema composto por operações para a realização da atividade a partir da realização dos componentes da ação que se passa a ser: orientação, execução e controle. Nessa perspectiva, desenvolveu-se a aplicação das operações como sistema das ações para a formação de uma nova habilidade que se configura na formação do conceito a ser apropriado. As etapas operacionais foram compostas pelos seguintes passos de acordo com o esquema 1, que constitui a assimilação de uma atividade para formação de uma nova habilidade a partir da teoria de Galperin.

Esquema 01 - Representação das etapas de assimilação de uma habilidade.

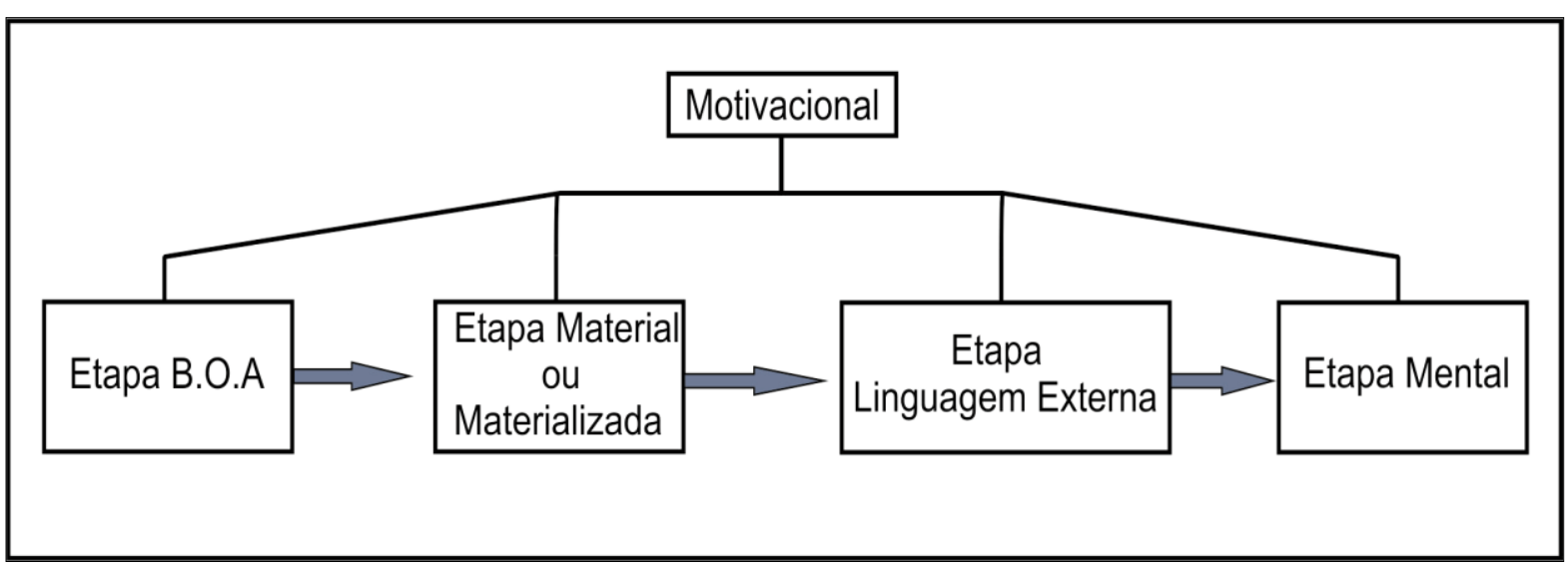

Fonte: Núñez, 2009, (adaptado).

Segundo Pereira (2013), a formação das ações mentais e dos conceitos 
por meio da motivação da aprendizagem a partir da Base de Orientação da Ação (BOA) e das etapas de formação da ação, Galperin enfatiza o processo de internalização para a compreensão do conceito. A partir desta representação das etapas de assimilação de uma habilidade na formação de conceitos, faz-se necessário a compreensão do todo a partir das partes, ou seja, compreender as etapas propostas por Galperin e suas especificidades que as compõem:

\subsection{Etapa 1 - Desenvolvimento na etapa motivacional}

De acordo com Talízina (1988), nessa etapa motivacional, a tarefa principal, passa a ser a criação de uma motivação necessária no estudante, a existência de motivos necessários para que os estudantes adotem a tarefa de estudo e cumpram a atividade que lhes é adequada.

Desta forma, nessa etapa motivacional, iniciou-se com um diálogo sobre dois textos, com a intenção de discutir episódios históricos na construção de teorias científicas a partir da inserção de dois acontecimentos históricos fundamentados em sonhos: o primeiro texto, denominado de Texto A, retrata um breve histórico sobre a descoberta e organização da Tabela Periódica pelo cientista russo Dmitri Ivanovich Mendeleev, e o segundo texto, denominado de Texto B, traz um relato histórico sobre a descoberta da estrutura molecular do benzeno, relatado pelo químico orgânico russo Friedrich August Kekulé, quadro 1.

Quadro 1. Textos motivacionais A e B.

\begin{tabular}{|c|c|}
\hline TEXTO A & TEXTO B \\
\hline $\begin{array}{l}\text { Conta à história que em 1869, Mendeleiev, } \\
\text { vencido pelo cansaço depois de trabalhar sem } \\
\text { intervalo durante três dias e três noites, } \\
\text { adormeceu. O mesmo debruçou-se, apoiando } \\
\text { a cabeça nos braços em meio aos cartões } \\
\text { espalhados em sua mesa, logo adormeceu } \\
\text { imediatamente, foi quando teve um sonho. } \\
\text { Esse episódio é a base para a organização dos } \\
\text { elementos químicos } \\
\text { "vi num sonho uma tabela em que } \\
\text { todos os elementos se encaixavam } \\
\text { como requerido. Ao despertar, escrevi- }\end{array}$ & $\begin{array}{l}\text { Sonho de Kekulé "estrutura do benzeno" } \\
\text { Enquanto cortejando Stephanie, no inverno de } \\
\text { 1861-1862, Kekulé começou a trabalhar na } \\
\text { primeira parte do segundo volume de seu livro. } \\
\text { Se formos a acreditar que a famosa história } \\
\text { que ele contou, em 1890, foi provavelmente } \\
\text { neste momento, nos primeiros meses de 1862, } \\
\text { outra experiência eureka ocorreu. } \\
\text { "Durante minha residência em Ghent, na } \\
\text { Bélgica, eu morava em um elegante } \\
\text { apartamento de solteiro na rua principal. } \\
\text { No entanto, o meu trabalho estava situado }\end{array}$ \\
\hline
\end{tabular}


a imediatamente numa folha de papel". (p. 246)

Em seu sonho, Mendeleiev compreendera que, quando os elementos eram listados na ordem de seus pesos atômicos, suas propriedades se repetiam numa serie de intervalo periódico. Por essa razão, chamou sua descoberta de Tabela Periódica dos Elementos. (p.246).

Trecho extraído do Livro: STRATHERN, P. "O Sonho de Mendeleiev: A verdadeira história da Química. Editor, Rio de Janeiro, 2002. junto a um beco estreito e não tinha luz durante o dia. Para um químico que passa o dia no laboratório, esta não era uma desvantagem. Lá estava eu sentado, trabalhando no meu livro, mas não estava indo muito bem, minha mente estava em outras coisas. Virei a cadeira em direção à lareira e me afundei em meio-sono. Novamente os átomos se agitaram diante dos meus olhos. Desta vez, os grupos mais pequenos mantiveram-se modestamente no fundo. Olhar da minha mente, aguçada por repetidas visões de um tipo semelhante, agora distinguindo formas maiores numa variedade de combinações. Longas filas, muitas vezes se encaixavam mais densamente, tudo em movimento, girando e girando como cobras. Mas veja, o que foi isso? Uma das cobras havia tomado sua própria cauda, e a figura girou zombeteiramente diante dos meus olhos. Acordei como por um raio, e desta vez também, eu passei o resto da noite trabalhando a consequências da hipótese" (p. s/p). (Tradução nossa).

Trecho extraído do Livro: ROCKE, A. J. Image \& Reality: Kekulé, Kopp, and the scientific imagination, 1948.

Fonte: Elaborado pelos autores.

\subsection{Etapa 2 - Desenvolvimento: Base Orientadora da Ação (B.O.A)}

Para a primeira aproximação com da Base Orientadora da Ação, que tem como pressuposto o processo de caracterizações necessárias e suficientes na construção de conceitos, bem como o sistema elaborado que contempla as ações que determina toda a atividade a ser percorrida no processo de assimilação da nova habilidade, foi elaborado um cartão de estudo com um conjunto de operações na forma de sequência de ensino e aprendizagem, que contempla os passos que devem ser percorridos pelos estudantes, contendo as informações necessárias na construção de conceitos, quadro 2. 
Quadro 2. Cartão de estudo utilizado na formação de habilidade - Base Orientadora da Ação - B.O.A II.

\begin{tabular}{|c|c|}
\hline CONCEITO & \multirow[b]{2}{*}{ AÇÕES } \\
\hline $\begin{array}{c}\text { Características necessárias e } \\
\text { suficientes }\end{array}$ & \\
\hline $\begin{array}{l}\text { Faça uma releitura dos textos A e B. } \\
\text { Leia o texto apoio A. } \\
\text { Observe os modelos da estrutura } \\
\text { molecular do benzeno. } \\
\text { Leia o texto de apoio B. }\end{array}$ & $\begin{array}{l}\text { Faça uma reflexão detalhada dos textos: A e B; } \\
\text { Analisar no texto B e texto de apoio A, as } \\
\text { principais características presentes em relação } \\
\text { ao desenvolvimento do conhecimento científico. } \\
\text { Reflita sobre a afirmação presente no texto } \\
\text { de apoio B, em torno dos relatos de Kekulé. }\end{array}$ \\
\hline
\end{tabular}

Fonte: Elaborado pelos autores.

\subsection{Etapa 3 - Desenvolvimento na etapa materializada}

Nessa etapa, caracteriza-se através das ações sobre os objetos concretos, por sua manipulação física, seja na presença desses objetos ou por meio de suas representações materiais, como diagramas, mapas, imagens (TALÍZINA, 1988). Desta forma, os estudantes permaneceram organizados em grupos para a resolução das tarefas, ou seja, todos os estudantes resolveram suas tarefas com o auxílio do cartão de estudo, como também análise evolutiva das imagens das estruturas moleculares proposta pelo cientista August Kekulé durante sua vida acadêmica quadro 3, e desenvolveram reflexões em grupo sobre dois textos complementares, quadro 4.

Quadro 3. Evolução das estruturas moleculares construídas por August Kekulé.

\begin{tabular}{|c|c|}
\hline 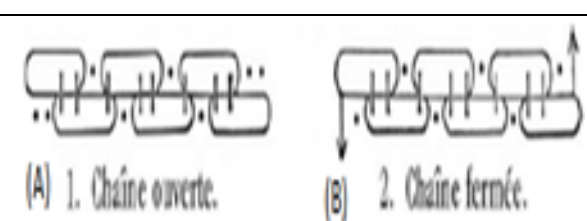 & $\begin{array}{l}\text { Representação (A) e (B): Ccadeia aberta e de } \\
\text { cadeia fechada - fórmulas salsicha de Kekulé } \\
\text { para o benzeno. }\end{array}$ \\
\hline & $\begin{array}{l}\text { Representação (C): Primeiro hexágono } \\
\text { benzeno de Kekulé. }\end{array}$ \\
\hline 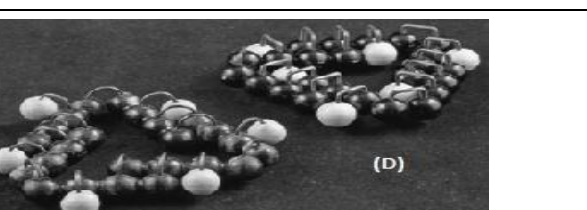 & $\begin{array}{l}\text { Representação (D): Dois anéis de benzeno } \\
\text { alternativas de Kekulé, formada por modelos } \\
\text { de salsicha originais. }\end{array}$ \\
\hline
\end{tabular}




Representação (E): Nova fórmula gráfico de
Kekulé para o benzeno.

Fonte: Elaborado pelos autores.

Quadro 4. Texto de apoio A e B.

\begin{tabular}{|c|c|}
\hline TEXTO DE APOIO A & TEXTO DE APOIO B \\
\hline $\begin{array}{l}\text { A partir do relato feito por Kekulé de como } \\
\text { o mesmo chegou ao hexágono era simples: } \\
\text { "O que mais eu tinha feito com as } \\
\text { unidades de afinidades extras?" } \\
\text { Ele quis dizer que se imagina alternando } \\
\text { simples e duplas ligações em seis carbonos, } \\
\text { seis moléculas de hidrogênios, um termina } \\
\text { com duas unidades de afinidade (valências) } \\
\text { deixou sobre, uma no primeiro átomo de } \\
\text { carbono e outro sobre o último. Por que não } \\
\text { dobrá-los em torno de um anel, assim } \\
\text { envolver cada unidade para formar uma } \\
\text { última ligação? (p. s/p). (Tradução nossa). }\end{array}$ & $\begin{array}{l}\text { Diante dos relatos feitos por Kekulé sobre } \\
\text { a formulação do benzeno, o cientista Kolbe } \\
\text { fez a seguinte afirmação: } \\
\text { "Terei prazer em tirar pecados em mim } \\
\text { mesmo..., mas querer fazer de mim um } \\
\text { espírita é quase um insulto. Se você acha } \\
\text { que você pode ver no interior da } \\
\text { molécula... e perceber como seus átomos } \\
\text { estão sentados, deitados, em pé... então } \\
\text { você é um espírita de primeira água... Vejo } \\
\text { agora que nós não entendemos um ao } \\
\text { outro". (p. s/p). (Tradução nossa). }\end{array}$ \\
\hline $\begin{array}{l}\text { Trecho extraído do Livro: ROCKE, A. J. } \\
\text { Image \& Reality: Kekulé, Kopp, and the } \\
\text { scientific imagination, } 1948 \text {. }\end{array}$ & $\begin{array}{l}\text { Trecho extraído do Livro: ROCKE, A. J. } \\
\text { Image \& Reality. Kekulé, Kopp, and the } \\
\text { scientific imagination, } 1948 \text {. }\end{array}$ \\
\hline
\end{tabular}

Fonte: Elaborado pelos autores.

\subsection{Etapa 4 - Desenvolvimento na etapa da linguagem externa}

$\mathrm{Na}$ etapa da Linguagem Externa, os estudantes permaneceram desenvolvendo as tarefas em grupos, a partir da elaboração de duas propostas para reflexão e análise dos acontecimentos históricos relatados nos textos $\mathrm{B}$ e o texto de apoio A e debatidos em sala de aula pelos grupos de estudantes. A orientação na resolução das tarefas nesta etapa, é que os estudantes pudessem interpretar os textos e expressar a partir da linguagem escrita os seus posicionamentos durante o processo.

Nessa etapa, segundo Núñez (2009), é necessária a intensificação das 
relações comunicativas numa dimensão pedagógica entre o professor e estudante, para que a ação sobre o objeto de estudo seja efetivada, considerando-se o fato já apontado de que a linguagem é o elemento mediador essencial entre o sujeito e o objeto de sua aprendizagem.

Em seguida houve o momento para a segunda reflexão, em que se configurou a partir do entendimento que os estudantes possuem em relações do texto B com os textos de apoio A e B, sobre a Natureza da Ciência - NdC. De acordo com Núñez (2009), as tarefas propostas devem ser resolvidas sem o apoio externo (cartão de estudo), como também as formas materializadas para realização da atividade, tendo em vista não ser mais necessário.

Desse modo, os participantes da pesquisa analisam duas situações-problemas decorrentes do desenvolvimento das reflexões, construindo uma visão maior do conceito a ser formado pelo processo de internalização da atividade proposta.

\subsection{Etapa 5 - Desenvolvimento da Etapa do Plano Mental}

De acordo com Núñez (2009), a "forma mental da ação é a etapa final no caminho da transformação da nova ação externa em interna” (p. 115). Nesse sentido, na transformação da ação verbal externa em mental, foi proposta aos estudantes que formulassem um conceito geral sobre o entendimento da formação do conhecimento científico 'para si', (estudantes), segundo a sua concepção construída ao decorrer do processo de assimilação como forma final da formação de conceitos, isto é, linguagem para consigo mesmo, que proporciona ao sujeito, estudante, a possibilidade de estruturar e reestruturar seu pensamento (VIGOTSKI, 1998).

\section{Resultados e discussões}

As etapas iniciais da atividade (Etapa motivacional; Base Orientadora da Ação tipo II, e a Etapa materializada), são caracterizadas como um 'guia' ou procedimentos a serem seguidos no percorrer da atividade. Nesse sentido, não serão discutidas neste espaço, uma vez que já foram descritas na metodologia, bem como, por não conterem elementos na forma verbal e ou escrita elaborada pelos estudantes pesquisados. 


\title{
4.1 Etapa da linguagem externa
}

A ação representada nesta etapa foi à forma verbal escrita. Nesse momento daremos início a análise da primeira reflexão dos acontecimentos históricos presentes no texto B e no texto de apoio A debatidos em sala de aula pelos grupos de estudantes.

Nesse sentido, obtiveram-se as seguintes reflexões referentes ao sonho de Kekulé sobre o surgimento do modelo da molécula do benzeno,

\begin{abstract}
No texto B e no texto de apoio A, podemos perceber que existe uma grande vontade de descobrir algo e que essa vontade era tão grande que estava presente em seus sonhos. Kekulé tornou-se um grande cientista e seus feitos foi de forma não convencional, pois por meio de sonho conseguiu definir suas hipóteses. Est. 5

[...] como o nosso pensamento se revelam através dos sonhos, hipóteses, ou seja, seus sonhos abrem caminhos para suas novas descobertas e os ajudam. Sendo que possa ou não, seus sonhos ter hipóteses e fundamentos. Est.4
\end{abstract}

Ao analisar estas falas, entende-se uma visão de conhecimento produzido que valoriza essencialmente a experimentação, quando refere-se a "forma não convencional" Est. 5, como também coloca a hipótese como orientadora de toda investigação. Nesse sentido percebe-se certa visão deformada da atividade científica, aparada na literatura, como sendo uma visão empírico-indutivista e ateórica. Segundo Cachapuz et al., (2011), nesse aspecto, o trabalho na ciência é desenvolvido como, "uma concepção que defende o papel da observação e da experimentação "neutro" (não influenciadas por ideias apriorísticas), esquecendo o papel essencial das hipóteses como focalizadoras da investigação e dos corpos coerentes de conhecimentos (teorias) disponíveis, que orientam todo o processo". (p.43).

O sonho como fator determinante para o desenvolvimento do trabalho científico neste contexto é apresentado pelo estudante em que descreve o cansaço como inibidor de pensamentos reflexivo, como também não descreve as suas tentativas e dúvidas anteriores em relação à estrutura do benzeno, destacando a visão rígida da atividade, 
Enquanto eles estavam trabalhando, as suas ideias estavam paradas por causa do desgaste do cérebro, mas quando ele descansou o seu cérebro, deu para formar ideias concretas. Est. 9

De acordo com Cachapuz et al., (2011), esta visão rígida, algorítmica, infalível do conhecimento científico é a concepção mais amplamente identificada na literatura, e também a que transmite uma ideia rígida do conhecimento científico como sendo infalível. Neste sentido, "refere-se ao "método científico" como uma sequência de etapas definidas, em que as observações e as "experiências rigorosas" desempenham um papel destacado à "exatidão e objetividade" dos resultados obtidos". (p.46).

Nesse sentido, e ainda dando continuidade as análises, duas falam chamam a atenção, ao tempo que descrevem um posicionamento mais elaborado sobre o episódio histórico descrito, ou seja, retratam a construção do conhecimento científico no decorrer da descoberta por August Kekulé. No entanto, sugue uma concepção ingênua, em que não apresentam indícios de estudos anteriores ao sonho, assim como, na fala do Est. 17, há elementos que relacionam a capacidade cognitiva ao gênero masculino, como também, as forças sobrenaturais,

Os dois textos relatam a descoberta de kekulé, o benzeno. E revela também a forma peculiar de como ele fez essa descoberta, em meio ao sono e a falta de concentração. É perceptível que quando o cansaço toma conta desses estudiosos, as ideias se fundem e cria uma forma, o que gera uma descoberta. Nós [os homens] temos o privilégio de nascer com inteligência e desvendar os mistérios da natureza que está dentro de nós. Est. 17

No texto B, explica que o químico estava muito cansado e se debruçou, foi nesse momento que ele teve o sonho do benzeno e quando ele acordou, colocou tudo em um papel. Mas ele ainda não havia chegado a uma imagem que fosse real, parecida com seu sonho. No texto de apoio A, diz que depois de algum tempo ele conseguiu enfim chegar a uma estrutura. Est. 18

Percebes-se, nas no texto dos estudantes acima, uma concepção individualista, em que segundo Cachapuz et al., (2011), os conhecimentos científicos aparecem como obras de gênios isolados, ignorando-se o papel do trabalho coletivo e cooperativo, dos intercâmbios entre equipes, sendo que em particular deixa-se acreditar que os resultados obtidos, por um só cientista podem 
bastar para verificar ou falsear uma hipótese ou inclusive toda uma teoria.

Neste momento, será analisada a segunda reflexão presente nos texto B e textos de apoio A e B, que tratou sobre a natureza da ciência, relatando as deferentes visões no processo de construção do conhecimento científico a partir do sonho, expondo um relato divergente feito pelo cientista Kolbe sobre o sonho de Kekulé.

Nesse sentido, as falas abaixo representam um recorte de alguns estudantes, a partir da atividade solicitada,

O conhecimento é a relação com suas hipóteses e sonhos. Mas no texto de apoio $\mathrm{B}$, faz discordâncias com os demais textos que relacionam suas descobertas e seus sonhos. Est. 4

Ambos os textos relatam o conhecimento científico e uma crítica feita a Kekulé por Kolbe, pois cada um adquiriu um conhecimento científico e usou para fazer suas teses e experimentos na ciência, ou seja, eles relacionavam seus conhecimentos na ciência. $\mathrm{Na}$ minha concepção, os cientistas de antigamente, ou de hoje, relacionam muito com ciências, até por que, o que eles fazem envolve ciência. Est. 15

Esses textos falam das descobertas científicas, das maneiras como eles pensaram para fazer esses projetos. É como se as descobertas fossem algo espiritual, onde se encontravam as respostas dentro de si próprias. Est. 14

No texto B, é que as cobras ficam em forma de benzeno e no texto de apoio $\mathrm{B}$, vem um cientista e crítica dizendo ser impossível, e que, só um espírita conseguiria ver os átomos. Est. 16

Ao analisar o pensamento descrito nesta etapa da linguagem externa, representada na forma verbal escrita, apenas quatro estudantes descreveram o pensamento com base em argumentação divergente de outros pesquisadores na construção científica.

Nesse sentido, um considerável número de estudantes (79\%) não soube refletir o posicionamento crítico e divergente em relação aos fatos transcritos nos textos, para tanto, inferimos que a ausência relacionada à compreensão dos textos está relacionada à falta de leitura e consequentemente de interpretação presente nas atividades escolares destes estudantes, reflexo do ensino de memorização das informações sem refletirem suas particularidades. 


\subsection{Etapa do Plano Mental}

Nesta última etapa da atividade - Plano Mental, as ações externas passam a se transformar em ações internas, ou seja, a interiorização dos novos conceitos formados pelos estudantes, em que a forma verbal escrita será a expressão 'final' do conceito. Nesse momento, os estudantes não tiveram o cartão de estudo como apoio externo, resolvendo a tarefa individualmente no plano da ação mental.

Desse modo, foi proposto aos estudantes que formulassem um conceito geral sobre o entendimento da formação do conhecimento científico 'para si', (estudantes), segundo a sua concepção construída ao decorrer do processo de assimilação como forma final da formação dos conceitos.

As análises das falas dos estudantes demonstram a forma que os mesmos compreendem a natureza do conhecimento científico, descrevendo os seus próprios conceitos como forma final do processo formativo.

Nesse sentido, seguem os seguintes conceitos,

Dá vontade de descobrir e querer algo. A meu ver, surge do sonho. Um sonho que tem que ser construído ou simplesmente pelo acaso. Est. 5

Diante do sonho dos cientistas. Eles dormiam demais. Est. 10

Através de muitos estudos e conhecimento. Também conta com as hipóteses e as críticas. O sonho também ajuda. Est. 16

Percebe-se nos resultados obtidos que, as primeiras três falas expressam o seu conceito de natureza do conhecimento científico relacionando aos sonhos, desta forma, para estes estudantes, no final do processo formativo, vêem os sonhos como a principal forma de construir novos conhecimentos na ciência, sem discutir os processos Históricos, Filosóficos e Sociais em que estão inseridos os pensamentos divergentes dos homens e ou mulheres. No entanto, o Est. 16, traz a hipótese, estudos anteriores e pensamentos divergentes como fatores determinantes na descoberta científica, não descartando a possibilidade do sonho dentro do processo de construção do conhecimento.

Dando continuidade, destacamos os seguintes conceitos apresentados pelos estudantes sobre a natureza do conhecimento científico, a compreender, 
Ela surge do pensamento científico do homem em geral, a formação vai de cada [cientista], pois cada um tem uma visão diferente, uma forma de se expressar. Então na minha opinião, a natureza do conhecimento científico na ciência surge através do saber, do raciocínio lógico. Est. 3

Ao analisar o conceito do Est. 3, chama a atenção o caráter do pensamento divergente sobre a construção do conhecimento das pessoas envolvida no 'fazer ciência', porém, percebe-se que nos três conceitos apresentados, há uma visão deformada, ou seja, empírico-indutivista e ateórica, que tem na experimentação a essência de toda atividade a partir do surgimento de mero raciocínio lógico, bem como um conhecimento pronto e acabado que destaca o papel da hipótese como eixo de toda investigação no processo de construção do conhecimento científico.

Para os estudantes 7 e 14, o conceito formado está pautado pelo aspecto cumulativo na formação do desenvolvimento científico, ou seja, a ciência tem um crescimento puramente linear, descartando todos os acontecimentos passados que se deram a partir de processos complexos, não demonstrando, no entanto, como estes conhecimentos foram alcançados, bem como as contestações na ciência, "surge a partir de estudos que são feitos por cientistas que fazem descobertas a partir de seus conhecimentos". Est. 7

Nessa discussão, nota-se que o Est. 14 reproduz a visão elitista do Est. 17 na etapa externa, quando descreve que "através dos pensamentos dos homens", como o único redentor da atividade científica,

Através dos pensamentos dos homens dentro do seu interior, onde se encontram as mais profundas ideias, que traz uma grande descoberta científica. [...] de suas imaginações, então a natureza científica consiste e surge através dessas ideias. Est. 14

No conceito a seguir, identificou-se uma visão exclusivamente analítica em que o conhecimento científico,

Consiste em tudo que podemos: estudar, pesquisar, analisar, ver outras espécies, como surgiu, os descentes entre outros; é onde nós vivemos, onde crescem diversas espécies, também algo que podemos criar [...] Est. 13 
Segundo Cachapuz et al., (2011, p.48), essa concepção do conhecimento científico sobre a ciência está "associada a uma incorreta apreciação do papel da análise no processo científico" Nesse sentido, Gil-Pérez et al., (2001), descrevem que esta concepção possui um caráter limitado, simplificador da construção do conhecimento científico, com também, esquece os esforços na elaboração de conhecimento passados, em que cada vez mais se ampliam.

A partir da concepção do Est. 13, percebem-se limitações e simplificação do conhecimento científico, como também não traz elementos que remetam aos esforços que os pesquisados passaram para a construção do conhecimento e ou ampliá-los no decorrer da História da Ciência.

Diante destes conceitos formados e após todo o processo de interiorização, ou seja, passagem do plano externo para o plano da ação interna, o conceito apresentado abaixo chama a atenção em uma definição descrita pelo est. 11 em que não foram identificados elementos que remetam a sinais de distorções do conhecimento científico,

A natureza do conhecimento na ciência surge a partir do momento em que o cientista no seu ambiente de trabalho faz pesquisas e estudos de um determinado fato ocorrido. $\mathrm{O}$ conhecimento científico também consiste na criação de teorias e conceitos feitos a partir de conhecimento anteriores, para novas justificativas de fatos que acontecem em nosso meio. Est. 11

A incorporação de elementos da História da Ciência no ensino, possibilita o entendimento do conhecimento científico como uma atividade humana, ressaltando quais seus interesses, aspectos sociais e relações Ciência, Tecnologia, Sociedade e Ambiente. Como também, ajudam a minimizar uma concepção reducionista, contribuindo para uma visão não deformada da ciência. Permitindo assim, segundo Borges (1996), entender o caráter provisório do conhecimento científico, reconhecendo a existência de crises importantes e remodelações profundas na evolução histórica dos conhecimentos científicos, as limitações dos conhecimentos atuais e as perspectivas abertas.

Ademais, quando o outro se sente parte do processo, se posicionando e 
utilizando-se de argumentos do tipo: "em nosso meio", passando a entender a importância dos fundamentos históricos e problemáticas da ciência e da construção do conhecimento, pois, evidenciam quais os problemas que geraram a construção do conhecimento, as dificuldades, contextualizando-os historicamente tornam-se mais representativa e consequentemente tornando-se um sujeito ativo no campo histórico, político e social (GIL-PÉREZ, 1993).

\section{Considerações finais}

Tendo em vista as análises realizadas nesta pesquisa, em que buscamos discutir a formação de conceitos dos estudantes do ensino médio sobre a natureza do conhecimento científico a partir da História da Química, relacionados ao episódio do "sonho" de August Kekulé, utilizando-se as possibilidades metodológicas da Teoria da Formação por Etapas das Ações Mentais de Galperin. Alguns pontos necessitam de uma maior atenção dentre esse se destaca a compreensão das concepções prévias que os estudantes possuem sobre como se dá a formação de conhecimentos científicos; bem como a sua análise, para posteriormente, seja estabelecida as Etapas das Ações Mentais proposta por Galperin.

Nesse contexto, durante a etapa motivacional, identificamos por parte dos estudantes, certa rejeição no desenvolvimento de leituras dos textos para a resolução das tarefas posteriores. Isso se torna um obstáculo na aprendizagem e no desenvolvimento de habilidades uma vez que, os estudantes precisam estar motivados em todos os aspectos das etapas posteriores, de modo que a realização da atividade não se torne de forma mecanizada e nem formal.

No desenvolvimento da Base Orientadora da Ação (B.O.A) do tipo II, em que direcionou o processo formativo dos conceitos, os estudantes percorreram sem dificuldade. Já na etapa da ação externa, os estudantes mostraram-se, com fragilidade relacionada à interpretação contextual, sendo um alto número de estudantes que não descreveu criticamente com base em argumentos significativos os fatos ocorridos nesta etapa. $\mathrm{Na}$ etapa da ação interna, todos os estudantes formularam o conceito sobre a natureza do conhecimento científico de forma generalizada e com independência, mas como constatados os estudantes 
apresentaram em comum uma visão distorcida do conhecimento científico. Dessa forma, a proposta de formação de conceito sobre a natureza do conhecimento científico, fundamentada na teoria de Galperin, passa a ser um caminho metodológico que possibilita o professor a desenvolver, proposta de sequência de ensino centrado na valorização argumentativa e do pensamento científico do estudante. Para tanto, contribui também com um possível rompimento de um ensino centrado na transmissão do conhecimento científico.

\section{Referências}

ABD-EL-KHALICK, F. Examining the sources for our understanding about science: enduring conflations and critical issues in research on nature of science in science education. International Journal of Science Education, Abingdon, v. 34, n. 3, p. 353-374, 2012. DOI: https://doi.org/10.1080/09500693.2011.629013.

ABD-EL-KHALICK, F., \& LEDERMAN, N. G. The influence of history of science courses on students' views of nature of science. Journal of Research in Science Teaching, Vol. 37, n. 10, p. 1057-1095, 2000. DOI: https://doi.org/10.1002/10982736(200012)37:10<1057::aid-tea3>3.0.c0;2-c.

BARDIN, L. Análise de conteúdo. São Paulo: Edições 70, 2012.

BORGES, M.R.R. Em debate: Cientificidade e Educação em Ciências. Porto Alegre: SE/CECIRS, 1996.

CACHAPUZ, A.; GIL-PEREZ, D; PESSOA DE CARVALHO, A.M.; PRAIA, J.; VILCHES, A.(Org). A necessária renovação do ensino das ciências. São Paulo: Cortez, 2011.

GALPERIN, P. Ya. Introducción a la Psicología. Editorial Pueblo y Educación: Ciudad dela Habana, 1982.

GALPERIN, P. Ya. Sobre la formación de las imágenes sensoriales y de los conceptos. In: Rojas, L. La formacion de las funciones psicologicas durante el desarrolo del niño. Tlaxcala: Universidad Autônoma de Tlaxcala, 2011.

GIL PÉREZ, D. Contribuición de La Historia y de La Filosofía de Las Ciencias Al Desarrolo de un Modelo de Enseñanza/Aprendizaje Como Investigación.

Enseñanza de Las Ciencias, v.11, n.2, p. 197-212, 1993.

GIL-PÉREZ, D.; MONTORO, I. F.; ALÍS, J. C.; CACHAPUZ, A.; PRAIA, J. Para uma imagem não deformada do trabalho científico. Ciência \& Educação, Bauru, v. 7, n. 2, p. 125-153, 2001. DOI: https://doi.org/10.1590/s1516-73132001000200001. 
HAENEN, J. Outlining the teaching-learning processes: Piotr Galperin's contribution. Learning and Instruction, v.11, p.157-170, 2001. DOI: https://doi.org/10.1016/s0959-4752(00)00020-7.

HODSON, D. Teaching and learning about science: language, theories, methods, history, traditions and values. Sense Publishers: Rotterdam, 2009. DOI: https://doi.org/10.1163/9789460910531.

MATTHEWS, M.R. Science teaching: the role of history and philosophy of science. New York: Routledge, 1994.

NÚÑEZ, I. B. Vygotsky, Leontiev, Galperin: formação de conceitos e princípios didáticos. Brasília: Liber Livro, 2009.

PEREIRA, J. E. Formação da habilidade de interpretar gráficos cartesianos em licenciados em Química segundo a teoria de P. ya. Galperin. 333f. Tese (doutorado em educação), Centro de educação, Universidade Federal do Rio Grande do Norte, Natal, 2013.

PORTO, P. A. História e Filosofia da Ciência no Ensino de Química: em busca dos objetivos educacionais da atualidade. In: SANTOS, W. L. P.; MALDANER, O. A. (Org). Ensino de Química em Foco. Ijuí: Ed. Unijuí, 2011.

SANTOS, W. L. P. Educação Científica na Perspectiva de Letramento como Prática Social: funções, princípios e desafios. Revista Brasileira de Educação, v. 12, n. 36, p.474-492, 2007. DOI: https://doi.org/10.1590/s1413-24782007000300007.

TALÍZINA, N. F. Métodos para La creación de programas de enseñanza. Camaguey. Editora da Universidad de Camaguey, 1987.

TALÍZINA, N. Psicología de la enseñanza. Moscou: Editorial Progreso, 1988.

VIGOTSKI, L. S. Pensamento e Linguagem. 2. ed. São Paulo: Martins Fontes, 1998. 